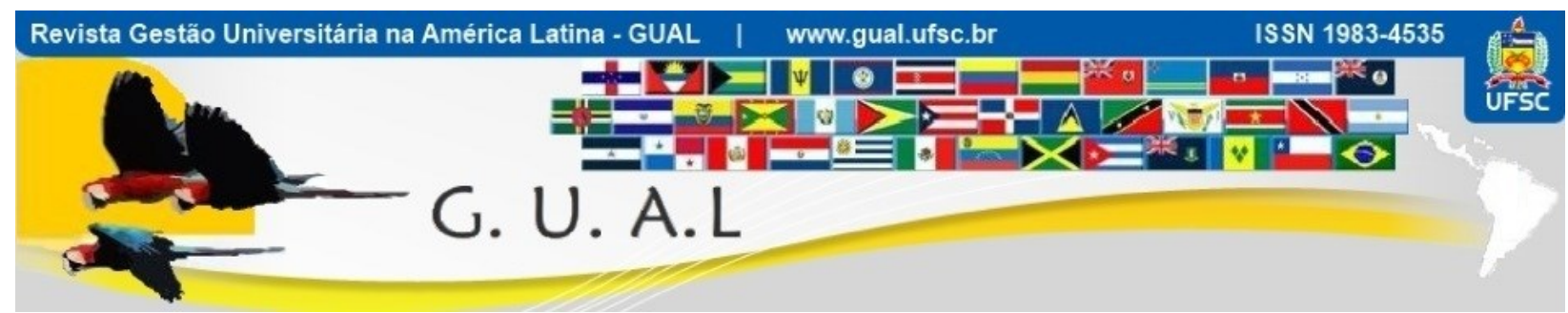

DOI: http://dx.doi.org/10.5007/1983-4535.2013v6n3p127

\title{
A GRADE CURRICULAR DOS CURSOS DE CIÊNCIAS CONTÁBEIS E OS RESULTADOS INSTITUCIONAIS NO ENADE: UM ESTUDO NAS DISCIPLINAS DA ÁREA DA CONTABILIDADE FINANCEIRA E DE ORÇAMENTO
}

\author{
THE CURRICULUM OF ACCOUNTING COURSES AND INSTITUTIONAL \\ OUTCOMES IN ENADE: A STUDY IN THE DISCIPLINES OF FINANCIAL \\ ACCOUNTING AND BUDGET
}

\author{
Alexandre Costa Quintana, Doutorando \\ Universidade Federal do Rio Grande - FURG \\ quintana@vetorial.net \\ Ana Néles Chaves Perazo, Graduada \\ Universidade Federal do Rio Grande - FURG. \\ ananelles@yahoo.com.br \\ Vera Lucia Pinheiro Fernandes, Graduada \\ Universidade Católica de Pelotas - UCPEL \\ vera.pf@brturbo.com.br
}

Recebido em 29/março/2013

Aprovado em 24/maio/2013

Sistema de Avaliação: Double Blind Review

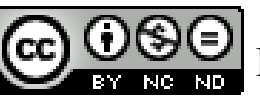

Esta obra está sob uma Licença Creative Commons Atribuição-Uso. 


\title{
RESUMO
}

O Exame Nacional de Desempenho de Estudantes (ENADE) avalia o rendimento dos alunos dos cursos de graduação, ingressantes e concluintes, em relação aos conteúdos programáticos dos cursos em que estão matriculados. Nesse sentido, ao analisar a carga horária das disciplinas da área da contabilidade financeira e orçamentária nos cursos de graduação em Ciências Contábeis, poderá se obter um panorama de como as Instituições de Ensino Superior (IES) estão provendo os seus estudantes sob este foco. O presente artigo tem como objetivo analisar a carga horária das disciplinas da área de contabilidade financeira e orçamentária nas IES, que ofertam o curso de Ciências Contábeis, com a intenção de investigar se existe uma relação com resultado do ENADE, nas instituições que obtiveram conceito entre 3 e 5 . Justifica-se a realização da pesquisa por contribuir com outros estudos voltados a área do ensino de contabilidade e sua evolução ao longo dos anos. Dado que a Universidade desempenha importante papel na formação dos futuros profissionais que em breve atuarão no mercado de trabalho e que deverão ter, além de uma base sólida voltada a profissão de sua escolha. Para alcançar os objetivos, realizou-se uma investigação documental nas grades curriculares das IES do Rio Grande do Sul, em confronto com os resultados obtidos por estas instituições nas provas do ENADE 2006 e 2009. Para testar a possível relação foi utilizado a correlação linear de Pearson. A análise mostrou uma correlação fraca entre a carga horária das disciplinas e o conceito obtido pelas IES estudadas. Em 2006, percebe que apesar de baixa existe alguma correlação. Por outro lado, em 2009, o índice indica que não há correlação entre as variáveis.

Palavras-chave: Carga-horária. Orçamento. Finanças. Desempenho Enade.

\begin{abstract}
The National Survey of Student Performance (ENADE) assesses student achievement of undergraduate courses, freshmen and, in relation to the syllabus of the courses in which they are enrolled. Accordingly, when considering the amount of teaching time in the area of financial accounting and budgeting in undergraduate courses in Accounting, you can get an overview of how Higher Education Institutions (HEIs) are providing their students in this light. This article aims to analyze the amount of teaching time in the area of financial accounting and budgeting in HEIs that offer the course in Accounting, with the intention to investigate whether there is a relationship with the ENADE result, institutions that obtained between concept 3 and 5. It is justified by the research contribute to other studies focused area of accounting education and its evolution over the years. Given that the University plays an important role in training future professionals who will act soon on the labor market and should have, in addition to a solid foundation facing the profession of your choice. To achieve the objectives, there was a documentary research in the curriculum of the university in Rio Grande do Sul, in comparison with the results obtained by these institutions in the evidence ENADE 2006 and 2009. To test the possible relationship was used to Pearson linear correlation. The analysis showed a weak correlation between the amount of teaching time and the concept obtained by the IES study. In 2006, despite low realizes there is some correlation. Moreover, in 2009, the index indicates that there is no correlation between the variables.
\end{abstract}

Keywords: Load-hourly. Budget. Finance. Performance Enade. 


\section{INTRODUÇÃO}

A preocupação com a qualidade do ensino tem sido objeto de estudo, tanto por parte da sociedade quanto pelos órgãos ligados à educação. Na metade da década de 90, o governo brasileiro iniciou um processo gradual de implementação de um sistema de avaliação do ensino superior (VERHINE, DANTAS e SOARES, 2005).

$\mathrm{Na}$ busca pela qualidade o governo brasileiro criou mecanismos para avaliação da Educação Superior, a Lei n ${ }^{0}$ 9.131, de 24 de novembro de 1995, cria o Exame Nacional de Cursos, popularmente conhecido como provão, sua função metodológica era aplicação de provas aos alunos concluintes dos cursos de graduação, tendo sua revogação em 2004 sendo substituído pelo ENADE.

A Lei $\mathrm{n}^{\mathrm{o}}$ 10.861/2004 determina que a "avaliação do desempenho dos estudantes dos cursos graduação será realizada mediante aplicação de Exame Nacional de Desempenho dos Estudantes - ENADE” (INEP, 2009, p.88).

O Exame Nacional de Desempenho de Estudantes (ENADE) avalia o rendimento dos alunos dos cursos de graduação, ingressantes e concluintes, em relação aos conteúdos programáticos dos cursos em que estão matriculados.

Nesse sentido, ao analisar a carga horária das disciplinas da área da contabilidade financeira e orçamentária nos cursos de graduação em Ciências Contábeis, poderá se obter um panorama de como as Instituições de Ensino Superior (IES) estão provendo, quantitativa e qualitativamente, os seus estudantes para que estejam preparados ou em condições para o exercício da profissão que escolheram, sob este foco (SILVA, GOMES e GUIMARÃES, 2008).

No desenvolvimento deste artigo, muitos foram os estudos encontrados que objetivaram estudar o desempenho dos alunos da graduação em Ciências Contábeis, a exemplo do trabalho realizado por Silva, Gomes e Guimarães (2008) que ao produzirem um estudo com o objetivo de analisar o resultado do desempenho dos estudantes de Ciências Contábeis que foram submetidos ao ENADE/2006, além de buscar estabelecer uma discussão crítico-sugestiva para os referidos cursos. O estudo contou com uma investigação documental nos relatórios do ENADE/2006, e bibliográfica referente ao Ensino da Contabilidade. Os resultados do referido estudo apontaram, através do perfil dos alunos, o pouco hábito pela leitura e pelo uso dos espaços das bibliotecas $(35,6 \%)$, o que explicou, significativamente, os $50 \%$ abaixo da média nacional sobre a análise das questões discursivas. No que se refere às 
questões objetivas de componente específico, os concluintes obtiveram bons resultados nas questões que envolviam conhecimento de Contabilidade Geral, mas apresentaram deficiência em Análise das Demonstrações Contábeis, Contabilidade Tributária e Auditoria.

Em um estudo realizado por Capacchi et al (2006), cujo objetivo foi analisar a estrutura curricular e os atuais desafios que se colocam na formação e na prática do bacharel em Ciências Contábeis, os autores encontraram dados que indicaram que os cursos de graduação pesquisados contemplavam um número limitado de disciplinas específicas da área das ciências contábeis, o que sugeriu a formação de profissionais generalistas e não especialistas, o que fragiliza o seu processo de ingresso no mercado de trabalho.

O presente estudo está focado no campo de finanças por ser amplo e dinâmico, afetando diretamente a vida de todas as pessoas e organizações. Na área contábil, a contabilidade financeira é voltada a usuários externos das informações contábeis, tais como acionistas controladores, gestores de fundos, órgãos que representam o governo e credores (SOUZA et al, 2008; GITMAN, 2010).

Diante do exposto, a questão que se pretende investigar é: Qual a carga horária das disciplinas da área de contabilidade financeira e orçamentária e sua relação com os resultados no Enade das IES que foram avaliadas com conceitos de 3 a 5 ?

Assim, com base na análise feita na grade curricular das IES que ofertam o curso de Ciências Contábeis e os resultados obtidos no Enade, o presente estudo tem como objetivo analisar a carga horária das disciplinas da área de contabilidade financeira e orçamentária nas Instituições de Ensino Superior (IES), que ofertam o curso de Ciências Contábeis, com a intenção de investigar se existe uma relação com resultado do Exame Nacional de Desempenho de Estudante (ENADE), nas instituições que obtiveram conceito entre 3 e 5.

Justifica-se a realização da pesquisa por contribuir com outros estudos voltados a área do ensino de contabilidade e sua evolução qualitativa e quantitativa ao longo dos anos. Dado que a Universidade desempenha importante papel na formação dos futuros profissionais que em breve atuarão no mercado de trabalho e que deverão ter, além de uma base sólida voltada a profissão de sua escolha, deverão também ter consciência de suas responsabilidades como ser social.

Alves, Corrar e Slomski (2004) corroboram a necessidade desse aperfeiçoamento quando afirmam que, dentre os objetivos de uma Instituição de Ensino Superior, certamente um dos mais importantes é a aprendizagem dos alunos. 
Com o intuito de responder as questões levantadas e também atingir os objetivos a que se propõe, o artigo está estruturado em cinco seções, sendo que a primeira é composta desta introdução que delineia a contextualização do problema de pesquisa. A segunda seção constitui-se da revisão literária, que contempla estudos anteriores que abordaram questões que norteiam o tema deste estudo. Na terceira seção estão apresentados os aspectos metodológicos, que descrevem o caminho metodológico seguido no desenvolvimento desta pesquisa. A apresentação e análise dos dados são expostas na quarta seção onde também estão descritos os resultados obtidos na pesquisa documental, a quinta seção é constituída pelas considerações finais. Ao final estão elencadas as referências que permeiam o aporte teórico desta pesquisa.

\section{FUNDAMENTAÇÃO TEÓRICA}

Nesta seção são abordados o ensino contábil de nível superior, a avaliação das instituições de educação superior e a contabilidade, gestão financeira e orçamento.

\subsection{O ENSINO CONTÁBIL DE NÍVEL SUPERIOR}

A Lei das Diretrizes e Bases da Educação Nacional (LDB), Lei nº 9.394 de 20 de dezembro de 1996, reafirma o direto do cidadão à Educação, já garantido pela Constituição Federal, enfatizando que esta educação para ser completa e formar para a cidadania deve ser de qualidade.

A resolução CNE/CES n ${ }^{\circ} 10$ de 10 de dezembro de 2004, que institui as diretrizes curriculares para o curso de Graduação em Ciências Contábeis, bacharelado determina:

\footnotetext{
Art. $3^{\mathrm{a}} \mathrm{O}$ curso de graduação em Ciências Contábeis deve possibilitar para que o futuro contador seja capacitado a:

I- compreender as questões científicas, técnicas, sociais, econômicas e financeiras, em âmbito nacional e internacional e nos diferentes modelos de organização;

II- apresentar pleno domínio das responsabilidades funcionais envolvendo apurações, auditorias, perícias, arbitragens, noções de atividades atuariais e de quantificações de informações financeiras, patrimoniais e governamentais, com plena utilização de inovações tecnológicas;

III- revelar capacidade crítico-analítica de avaliação, quanto às implicações organizacionais com advento da tecnologia da informação.
}

Em seu art. $5^{\mathrm{a}}$ a resolução $\mathrm{CNE} / \mathrm{CES} \mathrm{n}^{\mathrm{o}} 10$, determina como deve ser o projeto pedagógico e a organização curricular dos cursos de graduação em Ciências contábeis, para que seus conteúdos revelem conhecimento do cenário econômico e financeiro, nacional e 
internacional, de forma a proporcionar a harmonização das normas e padrões internacionais de contabilidade, em conformidade com a formação exigida pela Organização Mundial do Comércio e pelas peculiaridades das organizações governamentais, observando o perfil definido para o formando e que atendam aos seguintes campos interligados de formação:

I- conteúdos de Formação Básica: estudos relacionados com outra áreas do conhecimento, sobretudo Administração, Economia, Direito, Métodos Quantitativos, Matemática e Estatística;

II- conteúdos de Formação Profissional: estudos específicos atinentes às Teorias da Contabilidade, incluindo as noções das atividades atuariais e de qualificações de informações financeiras, patrimoniais e governamentais e não governamentais, de auditorias, perícias, arbitragens e controladoria, com suas aplicações peculiares ao setor público e privado;

III- conteúdos de Formação Teórico-Prática: Estágio Curricular Supervisionado, Atividades Complementares, Estudos Independentes, Conteúdos Optativos, Prática em Laboratório de Informática utilizando softwares atualizados para a contabilidade.

Demonstrando a importância e a relevância da formação Contábil no Brasil, foi sancionada pelo Presidente da República e publicada no Diário Oficial da União em junho de 2010, a Lei $\mathrm{n}^{\mathrm{0}}$ 12.249/2010 que altera as normas que regulamentam a profissão no Brasil. Com a nova lei, o Conselho Federal de Contabilidade (CFC) e os Conselhos Regionais de Contabilidade (CRCs) passam a ser responsáveis pela fiscalização do exercício da profissão Contábil. De acordo com o art. 12 desta Lei:

Os profissionais a que se refere esse Decreto-Lei somente poderão exercer a profissão após regular conclusão do Curso Bacharelado em Ciências Contábeis, reconhecido pelo Ministério da Educação, aprovação em Exame de suficiência e o registro no Conselho Regional de Contabilidade a que estiverem sujeitos.

A melhoria na qualidade de ensino não depende somente das mudanças curriculares e estruturais das instituições de ensino superior, mas principalmente, da seriedade, dedicação e compromisso assumido pelos professores na capacidade de formar bons profissionais e não apenas informá-los sobre alguns conteúdos (NOSSA, 1999).

No estudo realizado por Carlin e Martins (2006), com o objetivo de identificar e analisar os procedimentos, técnicas e métodos de ensino utilizados por vinte professores do Curso de Ciências Contábeis de quatro Escolas da Região da Grande São Paulo nos meses de março e abril de 2003, os resultados revelaram que lousa e transparências foram os recursos didáticos mais citados, e coerentemente, aulas expositivas seguidas de exercícios, as técnicas didáticas mais comuns. Seminários e o método de estudo de caso também receberam menções. Constataram também, que na maioria das vezes o conteúdo programático era 
desenvolvido a partir do método dedutivo, ou seja, do geral para o particular. Surpreendeu positivamente a expressiva proporção de docentes que entendiam como fator de sucesso didático a busca de equilíbrio entre características comportamentais e conhecimentos técnicos. $\mathrm{O}$ esforço e a participação sintetizou o esperado de um bom aluno. $\mathrm{O}$ interesse e entusiasmo revelados pelos participantes da pesquisa sugeriram o aprofundamento dos achados $\mathrm{e}$ investigações sistemáticas sobre o ensino da contabilidade. Para atingir a proposta do estudo, os autores construíram um formulário com base no referencial teórico sobre concepções de currículos, métodos e técnicas de ensino e aplicaram aos docentes.

Com o objetivo analisar o perfil dos professores de ensino superior, a partir da importância atribuída pelos estudantes de Contabilidade a um conjunto de cinco competências demandadas pelo trabalho docente (didática, relacionamento, exigência, conhecimento teórico e experiência de mercado). Gradvohl, Lopes e Costa (2009) realizaram um estudo de campo junto a uma amostra de 148 estudantes de cursos de graduação em Contabilidade, em instituições públicas e privadas da cidade de Fortaleza. Os dados foram avaliados através de técnicas descritivas e de análise conjunta. Nas análises descritiva e conjunta, os autores verificaram que a didática foi a competência docente de maior importância, seguida pelo conhecimento teórico. Especificamente por análise conjunta, foram procedidas verificações por categoria de variáveis qualitativas, tendo se apurado que, apesar de se manter a ordem de importância, os pesos relativos de cada competência variaram de acordo com o tipo de instituição, a metade do curso, o sexo, e a condição quanto ao trabalho dos estudantes.

Em uma pesquisa aplicada elaborada principalmente a partir de dados qualitativos realizada por Cruz et al (2009), que teve como objetivo principal apresentar uma aplicação das ferramentas do Processo de Raciocínio da Teoria das Restrições, desenvolvida por Eliyahu Goldratt, à avaliação dos resultados do Curso de Ciências Contábeis no ENADE, com vistas a identificar as possíveis causas dos resultados obtidos e propor caminhos para a busca de uma melhor avaliação, dentre outros aspectos, os resultados obtidos demonstraram que o curso de Ciências Contábeis apresentava baixa atratividade acadêmica, que se reflete também em reduzidos Programas de Pós-Graduação Stricto Sensu em Ciências Contábeis no Brasil, baixa titulação dos docentes e reduzida prática de pesquisa e extensão no curso. 


\subsection{AVALIAÇÕES DAS INSTITUIÇÕES DE EDUCAÇÃO SUPERIOR}

O processo de avaliação da educação superior no Brasil apresenta uma trajetória bastante rica e, inclusive, inovadora no que diz respeito à sua proposta de considerar o processo na sua totalidade.

Criado pela Lei $n^{\circ}$ 10.861, de 14 de abril de 2004, o Sistema Nacional de Avaliação da Educação Superior (SINAES) é formado por três componentes principais: a avaliação das instituições, dos cursos e do desempenho dos estudantes. O SINAES avalia todos os aspectos que giram em torno dos seguintes eixos: o ensino, a pesquisa, a extensão, a responsabilidade social, o desempenho dos alunos, a gestão da instituição, o corpo docente, as instalações e vários outros aspectos. Ele possui uma série de instrumentos complementares: auto-avaliação, avaliação externa, ENADE, Avaliação dos cursos de graduação e instrumentos de informação (censo e cadastro). Os resultados das avaliações possibilitam traçar um panorama da qualidade dos cursos e instituições de educação superior no País. Os processos avaliativos são coordenados e supervisionados pela Comissão Nacional de Avaliação da Educação Superior (CONAES). A operacionalização é de responsabilidade do Instituto Nacional de Estudos e Pesquisa Educacionais Aluísio Teixeira (INEP).Os instrumentos que subsidiam a produção de indicadores de qualidade e os processos de avaliação de cursos desenvolvidos pelo Inep são o Exame Nacional de Desempenho de Estudantes (Enade) e as avaliações in loco realizadas pelas comissões de especialistas.

O Exame Nacional de Desempenho de Estudantes (Enade), que integra o Sistema Nacional de Avaliação da Educação Superior (Sinaes), tem o objetivo de aferir o rendimento dos alunos dos cursos de graduação em relação aos conteúdos programáticos, suas habilidades e competências. (INEP, 2012)

As informações obtidas com o Sinaes são utilizadas pelas IES, para orientação da sua eficácia institucional e efetividade acadêmica e social; pelos órgãos governamentais para orientar políticas públicas e pelos estudantes, pais de alunos, instituições acadêmicas e público em geral, para orientar suas decisões quanto à realidade dos cursos e das instituições. (INEP 2012).

Para Ribeiro e Costa (2002), a avaliação institucional parte de uma construção coletiva de questionamentos e hipóteses. É uma resposta ao desejo de ruptura das "mesmices", colocando em movimento, estudos, análises, reflexões, e juízo de valor que tenham força de 
transformação na qualidade das IES e no seu contexto, na melhoria dos processos e das relações psicossociais.

A avaliação da eficácia educacional fornece um feedback de vital importância para Instituições de Ensino Superior. Ele também fornece informações importantes para partes interessadas externas, como os futuros alunos, pais, entidades governamentais e locais reguladoras, organizações de acreditação profissional e regional, e representantes dos trabalhadores. No entanto, a seleção de indicadores apropriados de eficácia educacional de programas e instituições é uma tarefa difícil, especialmente quando os critérios de eficácia não estão bem definidos (PRASLOVA, 2010).

Nesse sentido, a avaliação usa da obtenção de dados quantitativos e qualitativos sobre estudantes, professores, estrutura organizacional dos recursos físicos e materiais, as práticas de gestão, a produtividade de cursos, e dos professores entre outros com objetivo de emitir juízo valorativo e tomar decisões em relação ao desenvolvimento da instituição.

Alves, Corrar e Slomski (2004) desenvolveram um estudo empírico que teve como objetivo comparar o desempenho de alunos dos cursos de graduação em Ciências Contábeis no Brasil levando-se em consideração determinados aspectos da docência e de outros recursos educacionais, de modo a verificar o possível impacto destes fatores sobre o desempenho dos discentes. Através dos resultados obtidos, constatou-se que os professores tiveram influência no desempenho dos seus educandos, sob três aspectos: domínio atualizado das disciplinas ministradas, técnicas de ensino empregadas e recursos didáticos utilizados. Além disso, o acesso a microcomputadores também impactou o desempenho dos discentes, no entanto, o mesmo não aconteceu em relação às condições físicas da biblioteca para estudo.

Complementando a questão da avaliação do ensino superior, deve-se ressaltar a importância da prestação de contas, o que está intimamente relacionado com a avaliação da eficiência, eficácia e desempenho, ou seja, requer provar que o ensino superior tem alcançado os resultados planejados e o desempenho esperado de forma eficaz. Destacando a efíciência e eficácia e enfatizando os resultados que representam características básicas de prestação de contas no ensino superior. Avaliação do ensino superior é a principal abordagem para a responsabilidade de execução, bem como um meio básico de garantia de qualidade. A garantia de qualidade por meio de avaliações reflete uma nova cultura de responsabilidade na gestão do ensino superior. A complexidade inerente ao processo ensino superior determina a dificuldade de responsabilizar e medir o desempenho (KAI, 2009). 


\subsection{CONTABILIDADE, GESTÃO FINANCEIRA E ORÇAMENTO}

O papel do contador nas empresas pode ser de grande relevância, devido à variedade de saberes das diversas áreas do conhecimento que foram contempladas na grade curricular durante sua formação na graduação, o que poderá contribuir para o aprimoramento da sua capacidade de projetar, coordenar e controlar processos tanto de gestão financeira quanto orçamentária e ainda analisar e interpretaras modificações que ocorrem sob o aspecto econômico, financeiro e patrimonial das empresas. Assim, a contabilidade e os contadores vem sendo cada vez mais requisitados a suprir toda a organização com melhores serviços e informações. O contador deixa de ser o guarda livros da empresa, como profissional ele é solicitado a ter informações precisas que auxiliem os gestores em suas decisões.

Albrecht e Sack (2000) realizaram uma pesquisa nos Estados Unidos com profissionais e educadores da área contábil, e identificaram a necessidade do desenvolvimento de conhecimentos mais amplos do que aqueles relacionados a contabilidade tributária e fiscal. Quando perguntados sobre quais seriam as atividade que os graduandos em contabilidade estariam realizando no futuro, os profissionais contábeis, indicaram que os serviços mais demandados seriam, nesta ordem: 1) Análise Financeira; 2) Planejamento Financeiro; 3) Elaboração das Demonstrações Contábeis; 4) Consultoria Estratégica; e 5) Consultoria de Sistemas.

Para Iudícibus; Martins e Gelbcke (2010) a contabilidade é objetivamente, um sistema de informação e avaliação destinado a prover seus usuários com demonstrações e análise de natureza econômica, financeira, física e de produtividade, com relação à entidade objeto de contabilização. Os autores ainda enfatizam que a contabilidade é uma ciência nitidamente social quanto à suas finalidades, mas, como metodologia de mensuração, abarca tanto o social quanto o quantitativo.

Segundo Gitman (2010), as atividades de finanças (tesoureiro) e contabilidade (controller) estão intimamente relacionadas e, via de regra se sobrepõem. Na verdade muitas vezes é difícil distinguir a gestão financeira da contabilidade. Em virtude da complexidade da economia, da expansão e competividade dos mercados, as empresas buscam cada vez mais instrumentos que as auxiliem no planejamento e controle de seus recursos para que estes sejam alocados de forma a diluir seus custos, pois o sucesso empresarial demanda cada vez mais o uso de práticas financeiras. A gestão financeira possui uma responsabilidade e um compromisso com a ética. 
O orçamento é um plano financeiro de uma instituição seja ela pública ou privada, para um determinado exercício. A administração de qualquer entidade pública ou privada, com ou sem fins lucrativos, deve estabelecer objetivos e traçar metas, que devem estar descritas em um plano financeiro, isto é, em moeda corrente, para que possam ser acompanhadas e avaliadas pelos gestores da entidade.

O orçamento é uma ferramenta gerencial e tem sido utilizado como técnica formal de programação das operações e do planejamento econômico e financeiro nas empresas desde as décadas de 1940 e 1950 (PADOVEZE e TARANTO, 2009).

\section{METODOLOGIA}

Com o propósito de analisar a carga horária das disciplinas da área de contabilidade financeira e orçamentária nas Instituições de Ensino Superior (IES) que ofertam o curso de Ciências Contábeis, realizou-se uma pesquisa com a finalidade de investigar de forma comparativa o desempenho dos estudantes no Exame Nacional de Desempenho de Estudante (ENADE) nas instituições que obtiveram conceito entre 3 e 5, no estado do Rio Grande do Sul.

Quanto aos objetivos a pesquisa classifica-se como descritiva que na concepção de Beuren (2008), tem como objetivo descrever as características de determinada população ou fenômeno ou estabelecimento de relações entre variáveis.

Quanto à abordagem do problema, a pesquisa classifica-se como quantitativa que de acordo com Beuren (2008), caracteriza-se pelo emprego de instrumentos estatísticos. Neste caso, foi utilizada a correlação linear de Pearson, que de acordo com Martins e Theóphilo (2009, p.130), é "um indicador da força de uma relação linear entre duas variáveis intervalares".

Foi desenvolvida uma pesquisa de campo que de acordo com Lakatos e Marconi (1991), é aquela utilizada com o objetivo de obter informações e/ou conhecimentos acerca de um problema, para o qual se procura uma resposta, ou de uma hipótese, que se queira comprovar, ou ainda, descobrir novos fenômenos ou as relações entre eles.

O presente estudo contou com uma população composta pelos cursos de Ciências Contábeis ofertados por IES públicas e privadas do estado do Rio Grande do Sul. A coleta de dados foi feita de maneira longitudinal. Os dados relacionados à carga horária das disciplinas de contabilidade financeira e orçamentária ofertadas nos cursos de Ciências contábeis foram 
obtidos por meio de consulta ao site das instituições pesquisadas de acordo com a acessibilidade.

A análise comparativa do desempenho dos estudantes no Exame Nacional de Desempenho de Estudante (ENADE) nas instituições que obtiveram conceito entre 3 e 5, foi realizada com a consulta ao site do Sistema Nacional de Ensino Superior SINAES.

Os cursos sem conceito (s/c) ou que não foi possível a identificação da carga horária em suas grades curriculares, foram excluídos do estudo, uma vez que não apresentam os dados necessários para o desenvolvimento das análises.

\section{ANÁLISE DOS DADOS}

Os dados coletados referem-se aos exames aplicados nos anos de 2006 e 2009. A estrutura curricular utilizada é aquela presente, atualmente, nos sites das instituições.

Em 2006, o grupo de instituições ficou composto por 35 instituições de ensino superior, sendo 32 privadas e 3 públicas, destas 3 são Centros Universitários, 1 instituto de ensino superior, 7 Faculdades e 24 universidades. Algumas instituições aparecem mais de uma vez na Figura 1, pois possuem Campus independentes. As informações relativas ao ano de 2006 estão descritas na Figura 1.

\begin{tabular}{|c|c|c|c|}
\hline $\begin{array}{c}\text { INSTITUIÇÕES DE ENSINO } \\
\text { SUPERIOR }\end{array}$ & SIGLA DA IE & $\begin{array}{c}\text { CARGA HORÁRIA DAS } \\
\text { DISCIPLINAS CONTAB. } \\
\text { FINANCEIRA E } \\
\text { ORÇAMENTÁRIA }\end{array}$ & $\begin{array}{c}\text { CONCEIT } \\
\text { O ENADE }\end{array}$ \\
\hline $\begin{array}{c}\text { CENTRO UNIVERSITÁRIO } \\
\text { FRANCISCANO }\end{array}$ & UNIFRA & 272 & 3 \\
\hline CENTRO UNIVERSITÁRIO LA SALLE & UNILASALLE & 120 & 3 \\
\hline CENTRO UNIVERSITÁRIO UNIVATES & UNIVATES & 300 & 3 \\
\hline $\begin{array}{c}\text { FACULDADE CAMAQÜENSE DE } \\
\text { CIÊNCIAS CONTÁBEIS E } \\
\text { ADMINISTRATIVAS }\end{array}$ & FACCCA & 256 & 3 \\
\hline $\begin{array}{c}\text { FACULDADE DE CIÊNCIAS } \\
\text { CONTÁBEIS E ADMINISTRATIVAS DE } \\
\text { TAQUARA }\end{array}$ & FACCAT & 240 & 4 \\
\hline $\begin{array}{c}\text { FACULDADE DE CIÊNCIAS } \\
\text { CONTÁBEIS E ADMINISTRATIVAS } \\
\text { SAिO JUDAS TADEU }\end{array}$ & FCCASJT & 360 & 4 \\
\hline $\begin{array}{c}\text { FACULDADE DOM BOSCO DE PORTO } \\
\text { ALEGRE }\end{array}$ & FDB & 204 & 3 \\
\hline $\begin{array}{c}\text { FACULDADE PORTO-ALEGRENSE DE } \\
\text { CIÊNCIAS CONTÁBEIS E } \\
\text { ADMINISTRATIVAS }\end{array}$ & FAPCCA & 304 & 320 \\
\hline $\begin{array}{c}\text { FACULDADES INTEGRADAS } \\
\text { MACHADO DE ASSIS }\end{array}$ & FIMA & & 3 \\
\hline
\end{tabular}




\begin{tabular}{|c|c|c|c|}
\hline FACULDADES RIOGRANDENSES & FARGS & 360 & 3 \\
\hline $\begin{array}{c}\text { FUNDAÇÃO UNIVERSIDADE } \\
\text { FEDERAL DO RIO GRANDE }\end{array}$ & FURG & 210 & 4 \\
\hline $\begin{array}{l}\text { INSTITUTO CENECISTA DE ENSINO } \\
\text { SUPERIOR DE SANTO ÂNGELO }\end{array}$ & IESA & 280 & 3 \\
\hline $\begin{array}{c}\text { PONTIFÍCIA UNIVERSIDADE } \\
\text { CATÓLICA DO RIO GRANDE DO SUL }\end{array}$ & PUCRS & 180 & 3 \\
\hline $\begin{array}{l}\text { UNIVERSIDADE CATÓLICA DE } \\
\text { PELOTAS }\end{array}$ & UCPEL & 420 & 3 \\
\hline $\begin{array}{l}\text { UNIVERSIDADE DA REGIÃO DA } \\
\text { CAMPANHA }\end{array}$ & URCAMP & 360 & 3 \\
\hline $\begin{array}{l}\text { UNIVERSIDADE DA REGIÃO DA } \\
\text { CAMPANHA }\end{array}$ & URCAMP & 360 & 3 \\
\hline UNIVERSIDADE DE CAXIAS DO SUL & UCS & 180 & 4 \\
\hline UNIVERSIDADE DE CAXIAS DO SUL & UCS & 180 & 3 \\
\hline UNIVERSIDADE DE CAXIAS DO SUL & UCS & 180 & 3 \\
\hline UNIVERSIDADE DE PASSO FUNDO & UPF & 540 & 4 \\
\hline UNIVERSIDADE DE PASSO FUNDO & UPF & 540 & 4 \\
\hline UNIVERSIDADE DE PASSO FUNDO & UPF & 540 & 5 \\
\hline UNIVERSIDADE DE PASSO FUNDO & UPF & 540 & 3 \\
\hline UNIVERSIDADE DE PASSO FUNDO & UPF & 540 & 4 \\
\hline $\begin{array}{l}\text { UNIVERSIDADE DE SANTA CRUZ DO } \\
\text { SUL }\end{array}$ & UNISC & 330 & 3 \\
\hline $\begin{array}{l}\text { UNIVERSIDADE DE SANTA CRUZ DO } \\
\text { SUL }\end{array}$ & UNISC & 330 & 3 \\
\hline $\begin{array}{c}\text { UNIVERSIDADE DO VALE DO RIO } \\
\text { DOS SINOS }\end{array}$ & UNISINOS & 600 & 4 \\
\hline $\begin{array}{l}\text { UNIVERSIDADE FEDERAL DE SANTA } \\
\text { MARIA }\end{array}$ & UFSM & 240 & 4 \\
\hline $\begin{array}{c}\text { UNIVERSIDADE FEDERAL DO RIO } \\
\text { GRANDE DO SUL }\end{array}$ & UFRGS & 660 & 5 \\
\hline $\begin{array}{c}\text { UNIVERSIDADE LUTERANA DO } \\
\text { BRASIL }\end{array}$ & ULBRA & 408 & 3 \\
\hline $\begin{array}{l}\text { UNIVERSIDADE REGIONAL DO } \\
\text { NOROESTE DO ESTADO DO RIO } \\
\text { GRANDE DO SUL }\end{array}$ & UNIJUI & 360 & 3 \\
\hline $\begin{array}{c}\text { UNIVERSIDADE REGIONAL } \\
\text { INTEGRADA DO ALTO URUGUAI E } \\
\text { DAS MISSÕES }\end{array}$ & URI & 300 & 3 \\
\hline $\begin{array}{c}\text { UNIVERSIDADE REGIONAL } \\
\text { INTEGRADA DO ALTO URUGUAI E } \\
\text { DAS MISSÕES }\end{array}$ & URI & 300 & 3 \\
\hline $\begin{array}{c}\text { UNIVERSIDADE REGIONAL } \\
\text { INTEGRADA DO ALTO URUGUAI E } \\
\text { DAS MISSÕES }\end{array}$ & URI & 300 & 4 \\
\hline $\begin{array}{c}\text { UNIVERSIDADE REGIONAL } \\
\text { INTEGRADA DO ALTO URUGUAI E } \\
\text { DAS MISSÕES }\end{array}$ & URI & 300 & 3 \\
\hline
\end{tabular}

Figura 1 Carga horária das disciplinas da área de contabilidade financeira e orçamentária e os conceitos obtidos pelas das IES no Enade em 2006

Fonte: Ministério da Educação - Sistema e-MEC e sitio das IES. 
$\mathrm{Na}$ Figura 1, pode-se constatar que em média a carga horária das disciplinas de contabilidade financeira e orçamentária representa 340 horas, compondo-se das disciplinas: contabilidade financeira, finanças empresariais, fundamentos de gestão financeira, administração financeira, análise e interpretação de demonstrações, mercado de capitais, análise de investimentos, orçamento empresarial, contabilidade orçamentária, análise orçamentária e de liquidez, entre outras.

Em relação a 2009, o grupo de instituições ficou composto por 36 instituições de ensino superior, sendo 32 privadas e 4 públicas, destas 4 são Centros Universitários, 1 instituto de ensino superior, 11 Faculdades e 20 universidades, divididas em seus respectivos Campus. As informações relativas ao ano de 2009 estão descritas no Figura 2.

\begin{tabular}{|c|c|c|c|}
\hline INSTITUIÇÕES DE ENSINO SUPERIOR & $\begin{array}{l}\text { SIGLA DA } \\
\text { IE }\end{array}$ & $\begin{array}{c}\text { CARGA HORÁRIA } \\
\text { DAS DISCIPLINAS } \\
\text { CONTAB. } \\
\text { FINANCEIRA E } \\
\text { ORÇAMENTÁRIA }\end{array}$ & $\begin{array}{l}\text { CONCEITO } \\
\text { ENADE }\end{array}$ \\
\hline UNIVERSIDADE FEDERAL DO RIO GRANDE & FURG & 210 & 5 \\
\hline $\begin{array}{l}\text { UNIVERSIDADE REGIONAL INTEGRADA DO } \\
\text { ALTO URUGUAI E DAS MISSÕES - URI }\end{array}$ & URI & 300 & 5 \\
\hline $\begin{array}{c}\text { UNIVERSIDADE FEDERAL DO RIO GRANDE } \\
\text { DO SUL }\end{array}$ & UFRGS & 660 & 5 \\
\hline UNIVERSIDADE FEDERAL DE SANTA MARIA & UFSM & 240 & 5 \\
\hline UNIVERSIDADE FEDERAL DE SANTA MARIA & UFSM & 240 & 5 \\
\hline UNIVERSIDADE DE CAXIAS DO SUL & UCS & 180 & 4 \\
\hline UNIVERSIDADE DE PASSO FUNDO & UPF & 540 & 4 \\
\hline $\begin{array}{l}\text { PONTIFÍCIA UNIVERSIDADE CATÓLICA DO } \\
\text { RIO GRANDE DO SUL }\end{array}$ & PUCRS & 180 & 4 \\
\hline UNIVERSIDADE DA REGIÃO DA CAMPANHA & URCAMP & 360 & 4 \\
\hline $\begin{array}{l}\text { UNIVERSIDADE REGIONAL INTEGRADA DO } \\
\text { ALTO URUGUAI E DAS MISSÕES } \\
\end{array}$ & URI & 300 & 4 \\
\hline UNIVERSIDADE DE CRUZ ALTA & UNICRUZ & 360 & 4 \\
\hline UNIVERSIDADE LUTERANA DO BRASIL & ULBRA & 408 & 4 \\
\hline $\begin{array}{l}\text { UNIVERSIDADE REGIONAL DO NOROESTE } \\
\text { DO ESTADO DO RIO GRANDE DO SUL }\end{array}$ & UNIJUI & 360 & 4 \\
\hline CENTRO UNIVERSITÁRIO UNIVATES & UNIVATES & 300 & 4 \\
\hline FACULDADES RIOGRANDENSES & FARGS & 360 & 4 \\
\hline FACULDADES MONTEIRO LOBATO & FATO & 360 & 4 \\
\hline FACULDADES INEDI & CESUCA & 324 & 4 \\
\hline FACULDADES PORTO-ALEGRENSES & FAPA & 304 & 4 \\
\hline UNIVERSIDADE DE CAXIAS DO SUL & UCS & 180 & 3 \\
\hline $\begin{array}{l}\text { UNIVERSIDADE DO VALE DO RIO DOS } \\
\text { SINOS }\end{array}$ & UNISINOS & 600 & 3 \\
\hline UNIVERSIDADE CATÓLICA DE PELOTAS & UCPEL & 420 & 3 \\
\hline UNIVERSIDADE DE PASSO FUNDO & UPF & 540 & 3 \\
\hline
\end{tabular}




\begin{tabular}{|c|c|c|c|}
\hline UNIVERSIDADE DE SANTA CRUZ DO SUL & UNISC & 330 & 3 \\
\hline UNIVERSIDADE DA REGIÃO DA CAMPANHA & URCAMP & 360 & 3 \\
\hline $\begin{array}{c}\text { UNIVERSIDADE REGIONAL INTEGRADA DO } \\
\text { ALTO URUGUAI E DAS MISSÕES }\end{array}$ & URI & 300 & 3 \\
\hline CENTRO UNIVERSITÁRIO FRANCISCANO & UNIFRA & 272 & 3 \\
\hline $\begin{array}{c}\text { FACULDADE CAMAQÜENSE DE CIÊNCIAS } \\
\text { CONTÁBEIS E ADMINISTRATIVAS }\end{array}$ & FACCCA & 256 & 3 \\
\hline CENTRO UNIVERSITÁRIO LA SALLE & $\begin{array}{c}\text { UNILASAL } \\
\text { LE }\end{array}$ & 120 & 3 \\
\hline $\begin{array}{c}\text { INSTITUTO CENECISTA DE ENSINO } \\
\text { SUPERIOR DE SANTO ÂNGELO }\end{array}$ & CNEC/IESA & 280 & 3 \\
\hline $\begin{array}{c}\text { FUNDAÇÃO EDUCACIONAL MACHADO DE } \\
\text { ASSIS }\end{array}$ & FEMA \\
\hline $\begin{array}{c}\text { FACELGRE } \\
\text { FACULDADE IDEAU }\end{array}$ & FDB & 240 & 3 \\
\hline FACULDADE SÃO FRANCISCO DE ASSIS. & UNIFIN & 256 & 3 \\
\hline $\begin{array}{c}\text { FACULDA } \\
\text { DE IDEAU }\end{array}$ & 216 & 3 \\
\hline $\begin{array}{c}\text { FACUTRO UNIVERSITÁRIO METODISTA } \\
\text { ADMINISTRATIVAS DE TAQUARA E }\end{array}$ & FACCAT & 252 & 3 \\
\hline $\begin{array}{c}\text { FACULDADE DE CIÊNCIAS CONTÁBEIS E } \\
\text { ADMINISTRATIVAS SÃO JUDAS TADEU }\end{array}$ & SJT & 360 & 3 \\
\hline
\end{tabular}

Figura 2 Carga horária das disciplinas da área de contabilidade financeira e orçamentária e os conceitos obtidos pelas das IES no Enade em 2009

Fonte: Ministério da Educação - Sistema e-MEC e sitio das IES

Na Figura 2, observa-se que aumentaram a quantidade de instituições com conceito 5 no ENADE, no entanto, em média a carga horária das disciplinas de contabilidade financeira e orçamentária reduziu para 316 horas.

Para processamento dos dados utilizou-se a análise de correlação linear, que foi utilizada para medir se o conceito obtido pelas IES na avaliação do ENADE guarda alguma relação com a carga horária das disciplinas de contabilidade financeira e orçamentária.

De acordo com Silva e Pinto (2010), a análise de correlação linear permite determinar o grau de relação entre duas variáveis x e y.

$\mathrm{O}$ valor de $\boldsymbol{r}(\mathrm{x}, \mathrm{y})$ pertencerá ao intervalo que poderá variar de $[-1,1]$ indicando que -1 indica uma perfeita correlação negativa, ou seja, a correlação é inversamente proporcional, e complementam afirmando que 1 indica que há uma perfeita relação positiva, ou seja, há uma relação ou covariação entre as variáveis diretamente proporcional. Se entretanto, $\boldsymbol{r}$ (x, y) for igual ou próximo de zero significa que não há correlação entre as variáveis.

A medida de correlação linear é dada pelo coeficiente de correlação, r (x,y), de acordo com a seguinte definição: 


$$
\mathbf{r}_{\mathbf{x y}}=\frac{\sum \mathbf{X Y} \cdot \frac{\left(\sum \mathbf{X}\right)\left(\sum \mathbf{Y}\right)}{\mathbf{n}}}{\sqrt{\left[\sum \mathbf{X}^{2}-\frac{\left(\sum \mathbf{X}\right)^{2}}{\mathbf{n}}\right]\left[\sum \mathbf{Y}^{2}-\frac{\left(\sum \mathbf{Y}\right)^{2}}{\mathbf{n}}\right]}}
$$

Onde:

X - é variável independente, representada pela carga horária das disciplinas de contabilidade financeira e orçamentária.

Y - é a variável dependente, que no estudo representa o conceito ENADE obtido pelas Instituições.

n - é o número de instituições relacionadas no estudo.

Para a confirmação dos resultados obtidos, utilizou-se o software Stata 12, e assim como nos cálculos, obteve-se como índice de correlação 0,4289 para o ano de 2006 e para 2009 apurou-se 0,1202 .

A análise mostrou uma correlação fraca entre a carga horária das disciplinas e o conceito obtido pelas IES estudadas. Em 2006, percebe que apesar de baixa existe alguma correlação. Por outro lado, em 2009, o índice indica que não há correlação entre as variáveis.

\section{CONSIDERAÇÕES FINAIS}

O presente estudo teve como objetivo analisar a carga horária das disciplinas da área de contabilidade financeira e orçamentária nas Instituições de Ensino Superior (IES) que ofertam o curso de Ciências Contábeis, com a finalidade de investigar de forma comparativa o desempenho dos estudantes no Exame Nacional de Desempenho de Estudante (ENADE) nas instituições que obtiveram conceito entre 3 e 5.

Os resultados auferidos pela análise estatística dos dados revelaram que não há significativa relação entre a carga horária das disciplinas de contabilidade financeira e orçamentária e o conceito Enade das IES, um dos prováveis motivos pode estar relacionado a carga horária destas disciplinas, representar em média pouco mais de $10 \%$ da carga horária total dos cursos, pois em 2006 a média foi 340 h e em 2009 chegou a 316, considerando que de acordo, com o determinado pelo Conselho Nacional de Educação, os cursos de Ciências Contábeis devem possuir carga horária mínima de 3.000 h. Também, pode ter reflexo, nos resultados do estudo, o número reduzido de questões da área de contabilidade financeira e orçamentária na prova do ENADE. 
Os resultados deste estudo estão relacionados com o estudo de Capacchi et al (2006), que encontraram dados que indicaram que os cursos de graduação em Ciências Contábeis apresentam um número limitado de disciplinas específicas da área contábil, como no caso, finanças e orçamento, o que sugeriu a formação de profissionais mais generalistas.

Sugere-se para um próximo estudo o uso de outras ferramentas estatísticas e ainda levar em consideração outros índices que também fazem parte da composição do conceito Enade, bem como estudos comparativos com um número maior de regiões do Brasil.

\section{REFERÊNCIAS}

ALBRECHT, W. Steve; SACK, Robert J. Accounting education: charting the course through a perilous future. Accounting Education Series, n. 16, 2000.

ALVES, C. V. O. ; CORRAR, L.J.; SLOMSKI, V. A docência e o desempenho dos alunos dos cursos de graduação em contabilidade no Brasil. In: CONGRESSO USP DE CONTROLADORIA E CONTABILIDADE, 4, 2004, São Paulo. Anais... São Paulo: USP, 2004.

BEUREN, I. M. et al. Como elaborar trabalhos monográficos em contabilidade: Teoria e Prática. São Paulo: Atlas, 2008.

BRASIL. Lei n. 12.249, de 11 de junho de 2010. Altera dos decretos-leis n. 9.295, de 27 de maio de 1946, 1.040, de 21 de outubro de 1969. Disponível em:

$<$ http://www.cfc.org.br/uparq/lei12249.pdf >. Acesso em 10 set 2012.

CAPACCHI, M. et al. A prática do ensino contábil no Estado do Rio Grande do Sul: uma análise da grade curricular frente às exigências legais e necessidades acadêmicas. In:

CONGRESSO ANPCONT, 1, 2006, Gramado. Anais... Gramado: Anpcont, 2006.

CARLIN, I. P.; MARTINS, G. de A. Métodos de Sucesso no Ensino da Contabilidade. Disponível em: $<$ http://www.fecap.br/extensao/artigoteca/Art_008.pdf $\geq$. Acesso em: 10/07/2012.

CELLA, G.; RODRIGUES, J.; NIYAMA, J. Contabilidade Internacional - análise dos periódicos internacionais sobre pesquisas em educação contábil face à convergência e globalização. Revista Contemporânea de Contabilidade, Florianópolis, 8, nov. 2011. Disponível em: < http://www.journal.ufsc.br/index.php/contabilidade/article/view/21758069.2011v8n15p177>. Acesso em: 10/09/2012.

CRUZ, et al. Uma análise do desempenho do curso de Ciências Contábeis no ENADE a partir do Processo de Raciocínio da Teoria das Restrições. Revista de Contabilidade - Ufba, Salvador, v. 3, n. 3, p. 33-48, set./dez. 2009. 
GRADVOHL, R, F.; LOPES, F, F, P; COSTA, F, J. O perfil do bom professor de contabilidade: uma análise a partir da perspectiva de alunos de cursos de graduação. In: CONGRESSO USP DE CONTROLADORIA E CONTABILIDADE, 9, 2009, São Paulo. Anais... São Paulo, USP, 2009. Disponível em:

$<$ http://www.congressousp.fipecafi.org/artigos92009/45.pdf $>$. Acesso em: 22/08/2012.

GITMAN, L. J. Princípios de Administração Financeira. 12. ed. São Paulo: Pearson Prentice Hall, 2010.

INSTITUTO NACIONAL DE ESTUDOS E PESQUISAS EDUCACIONAIS ANÍSIO TEIXEIRA - INEP. 2009. Cadastro das Instituições de Ensino Superior. Disponível em: $<$ http://www.educacaosuperior.inep.gov.br/funcional/lista_cursos.asp/> . Acesso em: $10 / 07 / 2012$

IUDÍCIBUS, S.; MARTINS, E.; GELBCKE, E. R. Manual de contabilidade das sociedades por ações: aplicável as demais sociedades. 7 ed. São Paulo: Atlas 2010.

KAI, J. A Critical Analysis of Accountability in Higher Education Its Relevance to Evaluation of Higher Education. Chinese Education \& Society, v. 42, n. 2, p.39-51, 2009.

LAKATOS, E. M.; MARCONI, M.A. Fundamentos de metodologia científica. 3. ed. São Paulo: Atlas, 1991.

MARTINS, G. A.; THEÓPHILO, C. R. Metodologia da investigação científica para ciências sociais aplicadas. 2.ed. São Paulo: Atlas, 2009.

NOSSA, V. Formação do Corpo Docente dos Cursos de Graduação em Contabilidade no Brasil: Uma Análise Crítica. Caderno de Estudos da FIPECAFI, São Paulo, n. 21, ago. 1999.

PADOVEZE, C. L.; TARANTO, F. C.. Orçamento Empresarial: novos conceitos e técnicas. São Paulo: Pearson Education do Brasil, 2009.

POLIDORI, M. M. et. al. Um olhar sobre a avaliação num contexto multidisciplinar. In: SEMINÁRIO DE PESQUISA EM EDUCAÇÃO DA REGIÃO SUL, 7, 2008, Itajaí. Anais... Itajaí: Univali, 2008.PORTAL INEP. Disponível em: $<$ http://portal.inep.gov.br/superiorsinaes>. Acesso em: 23 ago 2012.

PORTAL MEC. Disponível em:

$<$ http://portal.mec.gov.br/index.php/?id=12303\&option $=$ com content\&view $=$ article $>$. Acesso 23 ago 2012.

PRASLOVA, L. Adaptation of Kirkpatrick's four level model of training criteria to assessment of learning outcomes and program evaluation in Higher Education. Educational Assessment, Evaluation and Accountability, v. 22, n. 3, p. 215-225, 2010.

MEC. Resolução CNE/CES n. 10, de 16 de dezembro de 2004. Institui as Diretrizes Curriculares Nacionais para o Curso de Graduação em Ciências Contábeis, bacharelado, e dá 
outras providências. Disponível em $<$

http://portal.mec.gov.br/cne/arquivos/pdf/rces10 04.pdf>. Acesso em 10 set 2012.

RIBEIRO, C. M.; COSTA, E. M. de M. B. Avaliação institucional: O desenvolvimento humano enquanto percurso e destino. Avaliação, Campinas, v.7, n.4, p. 165-175, dez.2002.

SANTOS, D. F. et al. Perfil do profissional contábil: estudo comparativo entre as exigências do mercado de trabalho e a formação oferecida pelas instituições de ensino superior de Curitiba. Revista Contabilidade Contemporânea, Florianópolis, v.8, n.16, p. 137-152, jul./dez., 2011.

SILVA, A. C. R. , GOMES, S. M., GUIMARÃES, I. P. Educação em Contabilidade: Alguns Aspectos Crítico sugestivos do Exame Nacional de Desempenho dos Estudantes - ENADE/ 2006. In: CONGRESSO BRASILEIRO DE CONTABILIDADE, 18., 2008, Gramado.

Anais... Gramado: Conselho Federal de Contabilidade, 2008.

SILVA, C. S.; PINTO, S. S. Estatística volume II - Rio Grande. Editora da FURG, 2010.

SOUZA, A. A et al. Ensino da Contabilidade Gerencial: Estudo dos Cursos de Ciências Contábeis das Melhores Universidades Brasileiras. Revista Contemporânea de

Contabilidade, Florianópolis, v. 05, n.10, p. 69-90, Jul./Dez., 2008

VERHINE, R. E.; DANTAS. L. M. V.;SOARES, J. F. Do Provão ao ENADE: uma análisecomparativa dos exames nacionais utilizados no Ensino Superior Brasileiro. Ensaio: aval. pol. públ. Educ., Rio de Janeiro, v.14, n.52, p. 291-310, jul./set. 2006. Disponível em: <http://www.scielo.br/pdf/ensaio/v14n52/a02v1452.pdf >. Acesso em 10/10/2012. 